\title{
Vitamin D Supplementation for Nonspecific Musculoskeletal Pain: Ready for Prime Time?
}

Ann Fam Med 2012;10:iii. doi:10.1370/afm.1463.

$\mathrm{T}$ The Annals of Family Medicine encourages readers to develop a learning community of those seeking to improve health care and health through enhanced primary care. You can participate by conducting a RADICAL journal club and sharing the results of your discussions in the Annals online discussion for the featured articles. RADICAL is an acronym for Read, Ask, Discuss, Inquire, Collaborate, Act, and Learn. The word radical also indicates the need to engage diverse participants in thinking critically about important issues affecting primary care and then acting on those discussions. ${ }^{1}$

\section{HOW IT WORKS}

In each issue, the Annals selects an article or articles and provides discussion tips and questions. We encourage you to take a RADICAL approach to these materials and to post a summary of your conversation in our online discussion. (Open the article online and click on "TRACK Comments: Submit a response.") You can find discussion questions and more information online in at: http://www.AnnFamMed.org/AJC/.

\section{CURRENT SELECTION}

\section{Article for Discussion}

Schreuder F, Bernsen RMD, van der Wouden JC. Vitamin D supplementation for nonspecific muscuoskeletal pain in non-Western immigrants: a randomized controlled trial. Ann Fam Med. 2012;10(6):547-555.

\section{Discussion Tips}

Vitamin D seems to be emerging as a therapeutic or preventive intervention for many diseases. This earlyphase clinical trial evaluates the short-term effect of a fixed dose of vitamin $\mathrm{D}$ for a common primary care problem in a high-risk population. The article is rich with clinical, methodological, and mechanistic factors to consider.

\section{Discussion Questions}

- What question is asked by this study and why does it matter?
- How does this study advance beyond previous research and clinical practice on this topic?

- How strong is the study design for answering the question?

- To what degree can the findings be accounted for by:

1. How patients were selected, excluded, or lost to follow-up?

2. The dose and timing of the vitamin D supplementation?

3. How the main variables were measured? The duration of measurement?

4. Confounding (false attribution of causality because 2 variables discovered to be associated actually are associated with a 3rd factor)?

5. Chance?

6. How the findings were interpreted?

- What are the main study findings?

- How do you interpret the differences in the magnitude and clinical and statistical significance of the findings across the different outcomes and time periods?

- How applicable do you judge the findings to be to other patient populations?

- How comparable is the study sample to similar patients in your practice? What is your judgment about the transportability of the findings?

- What contextual factors are important for interpreting the findings?

- Are these findings ready for application in practice? How and with whom? What might the role of vitamin $D$ testing, parathyroid hormone testing, and/or clinical assessment be in targeting treatment?

- What are the next steps in interpreting or applying the findings?

- What researchable questions remain?

\section{References}

1. Stange KC, Miller WL, McLellan LA, et al. Annals Journal Club: It's time to get RADICAL. Ann Fam Med. 2006;4(3):196-197. http:// annfammed.org/content/4/3/196. 